\title{
Efficacy and safety of mineralocorticoid receptor antagonist therapy in heart failure with reduced ejection fraction
}

\author{
Arden R Barry BSc BSc(Pharm) PharmD ACPR ${ }^{1}$, Sheri L Koshman BScPharm PharmD ACPR ${ }^{2}$, \\ Glen J Pearson BSc BScPhm PharmD FCSHP2
}

\begin{abstract}
AR Barry, SL Koshman, GJ Pearson. Efficacy and safety of mineralocorticoid receptor antagonist therapy in heart failure with reduced ejection fraction. Curr Res Cardiol 2014;1(2):84-88.

OBJECTIVES: To summarize the efficacy and safety of mineralocorticoid receptor antagonists (MRAs) compared with placebo for the treatment of heart failure with reduced ejection fraction (HFrEF) by assessing clinically relevant end points of randomized controlled trials.

METHODS: The Medline, EMBASE, Cochrane Central Register of Controlled Trials, Cochrane Database of Systematic Reviews, ACP Journal Club, DARE and International Pharmaceutical Abstracts databases were searched from inception to June 2014. Three authors independently reviewed and identified relevant articles. Included were randomized, doubleblinded, placebo-controlled trials that investigated spironolactone or eplerenone in adult patients with HFrEF regardless of etiology or symptomatology. RESULTS: The search strategy identified 726 articles; three met the inclusion criteria and included a total of 11,032 participants. The primary
\end{abstract}

Ч eart failure (HF) is a clinical syndrome associated with significant 1 morbidity and mortality. The prevalence of HF is estimated to be 5.7 million cases in the United States (1). This has been steadily increasing over the past two decades, with one of every five men and women $>40$ years of age developing HF in their lifetime. HF is associated with significant morbidity and is responsible for approximately one million hospitalizations in the United States annually. It is also notable that the annual mortality rate associated with HF is estimated to be between $5 \%$ and $50 \%(1,2)$. Randomized controlled trials of pharmacological therapies have demonstrated reduced morbidity and mortality in HF with reduced ejection fraction (HFrEF) (ie, left ventricular ejection fraction $[\mathrm{LVEF}] \leq 40 \%$ ) with angiotensin-converting enzyme inhibitors, angiotensin II receptor blockers and beta-blockers (2-5). More recently, mineralocorticoid receptor antagonists (MRAs) have demonstrated further benefit at reducing mortality and morbidity in addition to established pharmacotherapy. Thus, current clinical practice guidelines advocate the use of MRAs in patients with HFrEF (3-5). However, guidelines often do not provide an adequate assessment of the potential risks of therapy compared with the potential benefits, and the liberal use of MRAs at a population-based level has been linked with an increase in hyperkalemia-associated death and hospitalization (6). Thus, the purpose of the present meta-analysis was to summarize both the safety and efficacy of MRAs, compared with placebo, in the treatment of HFrEF by assessing clinically relevant end points of randomized controlled trials.

\section{METHODS}

Data selection

A systematic search strategy was used with the aid of a medical librarian. The following databases were queried from inception to June outcome of death from any cause was statistically significantly reduced with MRAs over placebo (risk ratio [RR] 0.81 [95\% CI 0.74 to 0.88]; $\mathrm{P}<0.001$ ). Hyperkalemia (serum potassium $\geq 6.0 \mathrm{mmol} / \mathrm{L}$ ) was significantly higher with MRA therapy (RR 1.41 [95\% CI 1.16 to 1.72$]$; $\mathrm{P}<0.001$ ). Other clinically relevant safety outcomes were not consistently reported. With respect to efficacy, MRAs reduced cardiovascular mortality (RR 0.80 [95\% CI 0.73 to 0.87]; $\mathrm{P}<0.001$ ) and hospitalizations due to heart failure (RR 0.76 [95\% CI 0.64 to 0.90]; $\mathrm{P}=0.001$ ), but not all-cause hospitalization (RR 0.91 [95\% CI 0.79 to 1.06 ]; $\mathrm{P}=0.23$ ).

CONCLUSIONS: The present review highlights the benefit of MRAs across the spectrum of HFrEF despite a higher incidence of hyperkalemia. Therefore, MRA therapy should not be withheld from appropriately selected patients with HFrEF because the risk of adverse events does not appear to exceed the overall benefit in mortality reduction.

Key Words: Eplerenone; Heart failure; Mineralocorticoid receptor antagonist; Spironolactone

2014: Medline and Ovid Medline In-Process \& Other Non-Indexed Citations, EMBASE, Cochrane Central Register of Controlled Trials, Cochrane Database of Systematic Reviews, ACP Journal Club, DARE and International Pharmaceutical Abstracts. The search terms "aldosterone antagonist", "mineralocorticoid receptor antagonist", "spironolactone", "eplerenone", "heart failure", "ventricular dysfunction" and "myocardial infarction" were used. The search was limited to prospective, randomized, placebo-controlled trials involving human subjects published in English. A manual search of the references of relevant articles was also performed.

\section{Study inclusion and outcomes}

Studies were included if they compared spironolactone or eplerenone with placebo in adult ( $\geq 18$ years of age) patients with $\mathrm{HFrEF}$ (defined as symptomatic or asymptomatic patients with LVEF $\leq 40 \%$ ) that were $\geq 12$ weeks in duration. Only studies that reported $\geq 1$ clinically relevant end point(s) (defined as death from any cause, cardiovascular [CV] death, hospitalization for any cause or HF hospitalization) were included. The primary outcome was all-cause mortality. The incidence of hyperkalemia (defined as serum potassium level $\geq 6.0 \mathrm{mmol} / \mathrm{L}$ ) was included as the primary safety outcome. Other safety outcomes included renal dysfunction (defined as doubling of serum creatinine level from baseline), lightheadedness and syncope. Secondary efficacy outcomes included CV death, all-cause hospitalization and HF hospitalization.

Study selection and data extraction

The present meta-analysis used a three-step process for determining studies to be included. One author (ARB) initially screened all relevant titles and abstracts based on the general inclusion criteria (eg, randomized controlled trial, human subjects). The second step involved

${ }^{1}$ Pharmacy Services, Mazankowski Alberta Heart Institute, Alberta Health Services; ${ }^{2}$ Division of Cardiology, Faculty of Medicine Eु Dentistry, University of Alberta, Edmonton, Alberta

Correspondence: Dr Arden R Barry, Suite 0G1.01 WMC, 8440 - 112 Street Northwest, Edmonton, Alberta T6G $2 B 7$.

Telephone 780-407-1046, fax 780-407-7690, e-mail arden.barry@albertahealthservices.ca 
TABLE 1

Characteristics of included studies

\begin{tabular}{|c|c|c|c|}
\hline \multirow[b]{2}{*}{ Characteristic } & \multicolumn{3}{|c|}{ Author (reference) } \\
\hline & Pitt et al (8) & \multirow[t]{2}{*}{ Pitt et al (9) } & \multirow[t]{2}{*}{ Zannad et al (10) } \\
\hline $\mathrm{n}$ & 1663 & & \\
\hline Age, years, mean $\pm S D$ & $65 \pm 12$ & $64 \pm 12$ & $69 \pm 8$ \\
\hline Male sex, \% & 73 & 71 & 78 \\
\hline HF etiology (\%) & Ischemia (55), nonischemic (45) & Ischemia (100) & Ischemia (69), nonischemic (31) \\
\hline Follow-up & 24 months (mean) & 16 months (median) & 21 months (median) \\
\hline Mean LVEF, \%, mean \pm SD & $25 \pm 7$ & $33 \pm 6$ & $26 \pm 5$ \\
\hline New York Heart Association class & III-IV & Not reported & II \\
\hline Baseline ACEI, \% & 95 & \multirow{2}{*}{87} & 78 \\
\hline Baseline ARB, \% & Not reported & & 19 \\
\hline Baseline beta-blocker, \% & 11 & 75 & 87 \\
\hline Baseline diuretic, \% & 100 & 60 & 85 \\
\hline Intervention & $\begin{array}{l}\text { Spironolactone } 25 \mathrm{mg} \text { PO daily (increased } \\
\text { to } 50 \mathrm{mg} \text { PO daily if patient showed signs } \\
\text { or symptoms of HF progression without } \\
\text { evidence of hyperkalemia at } 8 \text { weeks) }\end{array}$ & $\begin{array}{l}\text { Eplerenone } 25 \mathrm{mg} \text { PO daily } \\
\text { (increased to } 50 \mathrm{mg} \text { PO daily if } \\
\mathrm{K} \leq 5.5 \mathrm{mmol} / \mathrm{L} \text { after } 4 \text { weeks) }\end{array}$ & $\begin{array}{l}\text { Eplerenone } 25 \mathrm{mg} \text { PO daily } \\
\text { (increased to } 50 \mathrm{mg} \text { PO daily if } \\
\mathrm{K} \leq 5.0 \mathrm{mmol} / \mathrm{L} \text { after } 4 \text { weeks) }\end{array}$ \\
\hline Jadad score & 5 & 5 & 5 \\
\hline
\end{tabular}

ACEI Angiotensin converting enzyme inhibitor; ARB Angiotensin receptor blocker; HF Heart failure; K Serum potassium level; LVEF Left ventricular ejection fraction; NR Not reported; PO Per oral

an independent assessment of the abstracts of the included articles by two authors (ARB, GJP). Finally, articles that met the inclusion criteria were independently reviewed in full by two authors (ARB, SLK). Any disagreement among the authors with respect to inclusion was discussed until consensus was reached. The following data were extracted from each study: study design, inclusion and exclusion criteria, randomization and allocation concealment, total number of participants, baseline characteristics, intervention, duration of followup and the prespecified outcomes.

\section{Statistical analysis}

The methodological quality of the included studies was assessed using the Jadad score (7). Analysis of the results was performed with Review Manager 5.1.4 (The Nordic Cochrane Centre, The Cochrane Collaboration, Denmark, 2011). A risk ratio (RR) for each of the outcomes was calculated using a Mantel-Haenszel random-effects model. Weighted mean differences, including 95\% CI, were calculated for each outcome. Statistical heterogeneity was assessed using the $\mathrm{I}^{2}$ statistic, in which $>50 \%$ was considered to be significantly heterogeneous; $\mathrm{P}<0.05$ was considered to be statistically significant.

\section{RESULTS}

The search yielded 726 articles, of which a total of 71 were identified to be potentially relevant and were screened via abstract. Of the these 71 articles, most trials were excluded due to lack of a randomized design. Only two trials were excluded based on language restriction. This yielded 12 articles, which were reviewed in full and matched to the inclusion criteria. A total of three articles met the inclusion criteria $(8-10)$. A flow diagram of the study selection process is presented in Figure 1. Each of the included trials had a Jadad score of 5, indicating high methodological quality. There were too few studies included to properly assess for publication bias.

The characteristics of the included studies are summarized in Table 1. The three included trials enrolled a total of 11,032 participants and all compared active treatment (eplerenone in two studies, spironolactone in one study) with placebo. One trial included patients with New York Heart Association (NYHA) class III-IV symptoms and one included patients with NYHA class II symptoms $(8,10)$. The third trial did not report the NYHA class of the participants (9). The primary etiology of HF across the trials was myocardial ischemia. The majority $(73 \%)$ of the trial participants were men, with a mean age

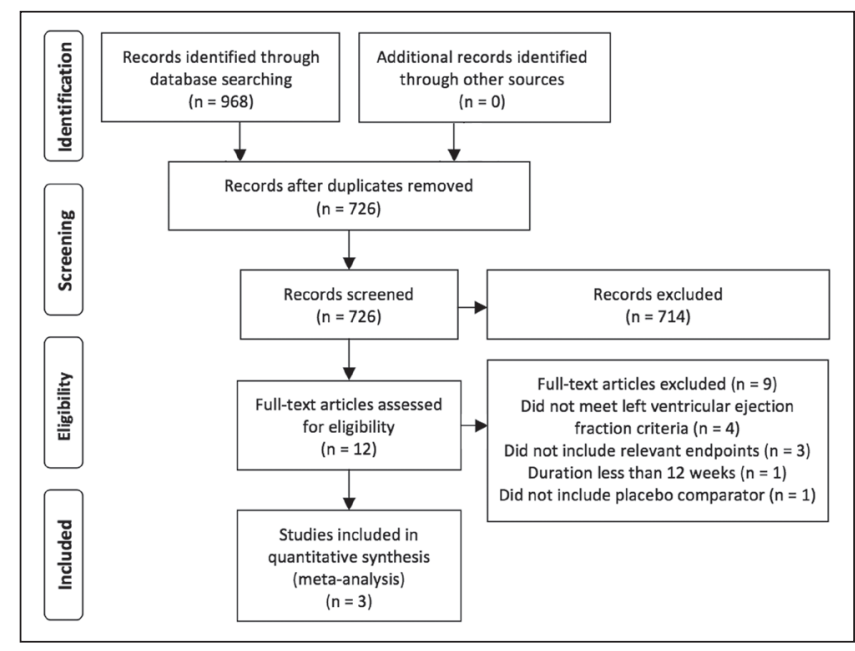

Figure 1) Study flow diagram

ranging from 64 to 69 years. Most participants were receiving current guideline-recommended pharmacotherapy for HF at baseline, with the exception of The Effect of Spironolactone on Morbidity and Mortality in Patients with Severe Heart Failure (RALES) trial (8). This trial was conducted in the era before the routine recommended use of betablockers in HFrEF; thus, only $11 \%$ of patients were receiving betablockers at baseline. Patient follow-up ranged from 16 to 24 months and all trials used an intention-to-treat analysis.

The primary outcome of all-cause mortality was statistically significantly reduced with MRAs over placebo, with an RR of $0.81(95 \% \mathrm{CI}$ 0.74 to 0.88 ); $\mathrm{P}<0.001 ; \mathrm{I}^{2}=24 \%$ (Figure 2). This benefit was consistent across all three studies. With respect to safety, the only outcome consistently reported across the trials was hyperkalemia, which was statistically significantly higher with MRAs compared with placebo (RR 1.41 [ $95 \%$ CI 1.16 to 1.72 ]; $\mathrm{P}<0.001 ; \mathrm{I}^{2}=0 \%$ ) (Figure 3). The incidence of renal dysfunction, as defined in the present study, was not reported in any of the trials; however, one trial reported renal failure, although it was not clearly defined and was not statistically different between groups (10). The incidence of lightheadedness or syncope was not reported in any of the trials. With respect to efficacy outcomes, MRAs were associated with a $20 \%$ relative risk reduction in CV 


\begin{tabular}{|c|c|c|c|c|c|c|c|c|}
\hline \multirow{2}{*}{ Study or Subgroup } & \multicolumn{2}{|c|}{ Aldosterone Antagonist } & \multicolumn{2}{|c|}{ Placebo } & \multirow{2}{*}{ Weight } & \multirow{2}{*}{$\begin{array}{c}\text { Risk Ratio } \\
\text { M-H, Random, } 95 \% \mathrm{Cl}\end{array}$} & \multirow{2}{*}{\multicolumn{2}{|c|}{$\begin{array}{c}\text { Risk Ratio } \\
\text { M-H, Random, } 95 \% \mathrm{CI}\end{array}$}} \\
\hline & Events & Total & & Total & & & & \\
\hline EMPHASIS-HF & 171 & 1364 & 213 & 1373 & $19.1 \%$ & $0.81[0.67,0.97]$ & $\longrightarrow-$ & \\
\hline EPHESUS & 478 & 3319 & 554 & 3313 & $42.1 \%$ & $0.86[0.77,0.96]$ & $\rightarrow-$ & \\
\hline Total $(95 \% \mathrm{CI})$ & & 5505 & & 5527 & $100.0 \%$ & $0.81[0.74,0.88]$ & & \\
\hline Total events & 933 & & 1153 & & & & & \\
\hline \multicolumn{7}{|c|}{ Heterogeneity: $\mathrm{Tau}^{2}=0.00 ; \mathrm{Chi}^{2}=2.64, \mathrm{df}=2(\mathrm{P}=0.27) ; \mathrm{I}^{2}=24 \%$} & $\frac{1}{0.5}$ & $\begin{array}{ll}1.5 & 1 \\
\end{array}$ \\
\hline
\end{tabular}

Figure 2) Forest plot for all-cause mortality. AA Aldosterone antagonist; EMPHASIS-HF The Eplerenone in Mild Patients Hospitalization and Survival Study in Heart Failure; EPHESUS Eplerenone, a Selective Aldosterone Blocker, in Patients with Left Ventricular Dysfunction after Myocardial Infarction; RALES The Effect of Spironolactone on Morbidity and Mortality in Patients with Severe Heart Failure

\begin{tabular}{|c|c|c|c|c|c|c|c|c|c|}
\hline Study or Subgroup & \multicolumn{2}{|c|}{ Aldosterone Antagonist } & Placebo & $\begin{array}{l}\text { bo } \\
\text { Total }\end{array}$ & Weight & $\begin{array}{l}\text { Risk Ratio } \\
\text { M-H, Random, } 95 \% \mathrm{CI}\end{array}$ & \multicolumn{3}{|c|}{$\begin{array}{l}\text { Risk Ratio } \\
\text { M-H, Random, } 95 \% \text { CI }\end{array}$} \\
\hline EPHESUS & 180 & 3307 & 126 & 3301 & $79.1 \%$ & $1.43[1.14,1.78]$ & & & - \\
\hline RALES & 14 & 822 & 10 & 841 & $6.0 \%$ & $1.43[0.64,3.21]$ & & & \\
\hline Total $(95 \% \mathrm{Cl})$ & & 5465 & & 5482 & $100.0 \%$ & $1.41[1.16,1.72]$ & & & \\
\hline Total events & 227 & & 161 & & & & & & \\
\hline \multicolumn{7}{|c|}{$\begin{array}{l}\text { Heterogeneity: } \text { Tau }^{2}=0.00 ; \mathrm{Chi}^{2}=0.07, \mathrm{df}=2(\mathrm{P}=0.97) ; \mathrm{I}^{2}=0 \% \\
\text { Test for overall effect: } \mathrm{Z}=3.41(\mathrm{P}=0.0007)\end{array}$} & 0.2 & $\begin{array}{c}0.5 \\
\text { Favours AA }\end{array}$ & $\begin{array}{cc}\frac{1}{2} & 5 \\
\text { Favours placebo }\end{array}$ \\
\hline
\end{tabular}

Figure 3) Forest plot for hyperkalemia. AA Aldosterone antagonist; EMPHASIS-HF The Eplerenone in Mild Patients Hospitalization and Survival Study in Heart Failure; EPHESUS Eplerenone, a Selective Aldosterone Blocker, in Patients with Left Ventricular Dysfunction after Myocardial Infarction; RALES The Effect of Spironolactone on Morbidity and Mortality in Patients with Severe Heart Failure

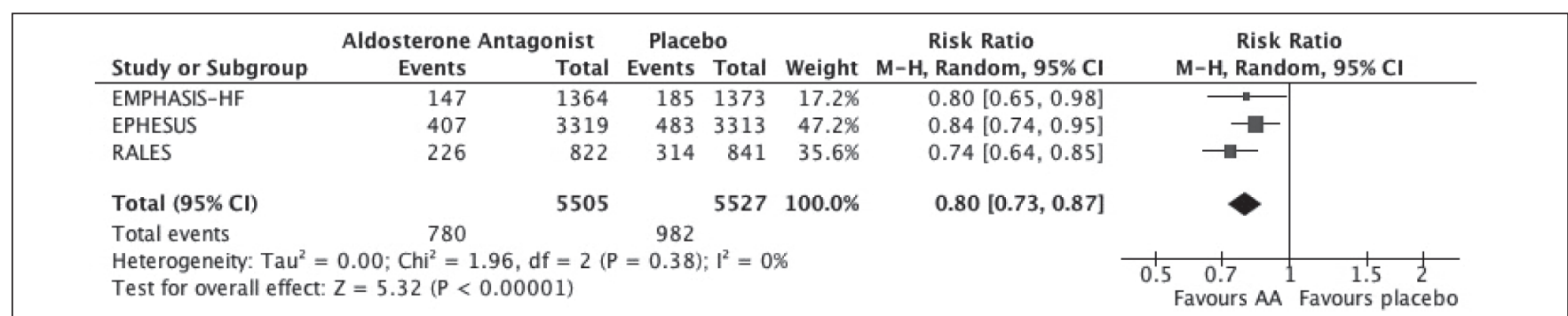

Figure 4) Forest plot for cardiovascular mortality. AA Aldosterone antagonist; EMPHASIS-HF The Eplerenone in Mild Patients Hospitalization and Survival Study in Heart Failure; EPHESUS Eplerenone, a Selective Aldosterone Blocker, in Patients with Left Ventricular Dysfunction after Myocardial Infarction; RALES The Effect of Spironolactone on Morbidity and Mortality in Patients with Severe Heart Failure

\begin{tabular}{|c|c|c|c|c|c|c|c|}
\hline Study or Subgroup & \multicolumn{2}{|c|}{ Aldosterone Antagonist } & \multicolumn{2}{|c|}{ Placebo } & Weight & $\begin{array}{l}\text { Risk Ratio } \\
\text { M-H, Random, } 95 \% \mathrm{Cl}\end{array}$ & $\begin{array}{l}\text { Risk Ratio } \\
\text { M-H, Random, } 95 \% \mathrm{Cl}\end{array}$ \\
\hline EMPHASIS-HF & 164 & 1364 & 253 & 1373 & $30.2 \%$ & $0.65[0.54,0.78]$ & $\rightarrow-$ \\
\hline EPHESUS & 345 & 3319 & 391 & 3313 & $35.5 \%$ & $0.88[0.77,1.01]$ & $\rightarrow$ \\
\hline Total $(95 \% \mathrm{CI})$ & & 5505 & & 5527 & $100.0 \%$ & $0.76[0.64,0.90]$ & \\
\hline Total events & 724 & & 944 & & & & \\
\hline \multicolumn{7}{|c|}{$\begin{array}{l}\text { Heterogeneity: } \operatorname{Tau}^{2}=0.02 ; \mathrm{Chi}^{2}=7.35, \mathrm{df}=2(\mathrm{P}=0.03) ; \mathrm{I}^{2}=73 \% \\
\text { Test for overall effect: } \mathrm{Z}=3.23(\mathrm{P}=0.001)\end{array}$} & \begin{tabular}{cc|cc}
1 & 1 & 1 & 1 \\
0.5 & 0.7 & 1.5 & 2 \\
Favours AA & Favours placebo
\end{tabular} \\
\hline
\end{tabular}

Figure 5) Forest plot for heart failure hospitalization. AA Aldosterone antagonist; EMPHASIS-HF The Eplerenone in Mild Patients Hospitalization and Survival Study in Heart Failure; EPHESUS Eplerenone, a Selective Aldosterone Blocker, in Patients with Left Ventricular Dysfunction after Myocardial Infarction; RALES The Effect of Spironolactone on Morbidity and Mortality in Patients with Severe Heart Failure

mortality (RR 0.80 [95\% CI 0.73 to 0.87 ]; $\mathrm{P}<0.001 ; \mathrm{I}^{2}=0 \%$ ) (Figure 4). Hospitalization due to HF was also reduced by $24 \%$ (RR 0.76 [95\% CI 0.64 to 0.90 ]; $\left.\mathrm{P}=0.001 ; \mathrm{I}^{2}=73 \%\right)$ but was associated with high statistical heterogeneity (Figure 5). The rate of hospitalization from any cause was only reported in two of the trials and was not statistically significantly different between groups (RR 0.91 [95\% CI 0.79 to 1.06]; $\mathrm{P}=0.23 ; \mathrm{I}^{2}=85 \%$ ) (Figure 6 ). Sensitivity analyses were not performed due to the small number of trials included.

\section{DISCUSSION}

The present meta-analysis of large, well-designed randomized controlled trials demonstrates that MRAs reduce all-cause mortality in adult patients with HFrEF. To our knowledge, the present review included the largest pooled patient population for MRAs in HFrEF, and is the first to include the Eplerenone in Patients with Systolic Heart Failure and Mild Symptoms (EMPHASIS-HF) trial (10). Overall, there was a $19 \%$ relative risk reduction observed in death from any cause in patients treated with an MRA compared with placebo. CV mortality was also reduced by $20 \%$. This was similar to the results of a systematic review published by Ezekowitz et al (11), which included approximately 10,000 patients and demonstrated a $20 \%$ reduction in all-cause mortality. The mechanism of how MRAs decrease mortality in HFrEF is unknown; however, it likely extends beyond the blocking of aldosterone-mediated retention of sodium and water. In 


\begin{tabular}{|c|c|c|c|c|c|c|c|}
\hline Study or Subgroup & \multicolumn{2}{|c|}{ Aldosterone Antagonist } & \multicolumn{2}{|c|}{ Placebo } & Weight & $\begin{array}{c}\text { Risk Ratio } \\
\text { M-H, Random, } 95 \% \mathrm{CI}\end{array}$ & $\begin{array}{c}\text { Risk Ratio } \\
\text { M-H, Random, 95\% CI }\end{array}$ \\
\hline EMPHASIS-HF & 408 & 1364 & 491 & 1373 & $45.2 \%$ & $0.84[0.75,0.93]$ & $-\square$ \\
\hline EPHESUS & 1493 & 3319 & 1526 & 3313 & $54.8 \%$ & $0.98[0.93,1.03]$ & \\
\hline Total $(95 \% \mathrm{Cl})$ & & 4683 & & 4686 & $100.0 \%$ & $0.91[0.78,1.06]$ & \\
\hline Total events & 1901 & & 2017 & & & & \\
\hline $\begin{array}{l}\text { Heterogeneity: } \mathrm{Tau}^{2} \\
\text { Test for overall effect }\end{array}$ & $\begin{array}{l}0.01 ; \text { Chi }^{2}=6 \\
\mathrm{Z}=1.21(\mathrm{P}=\end{array}$ & $=1($ & $=0.01)$ & $; I^{2}=$ & & & 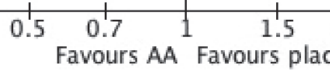 \\
\hline
\end{tabular}

Figure 6) Forest plot for all-cause hospitalization. AA Aldosterone antagonist; EMPHASIS-HF The Eplerenone in Mild Patients Hospitalization and Survival Study in Heart Failure; EPHESUS Eplerenone, a Selective Aldosterone Blocker, in Patients with Left Ventricular Dysfunction after Myocardial Infarction

animal models of HF, MRAs have been demonstrated to have a direct effect on pathogenic processes associated with HF, such as inhibiting catecholamine-mediated cardiac fibrosis, reducing superoxide formation and oxidative stress, increasing natriuresis and lowering left ventricular end diastolic pressure (12-15). These agents have also been associated with improved endothelial function and increased nitric oxide bioactivity in HF patients $(15,16)$.

The safety of MRAs in HFrEF must be interpreted with caution due to the incomplete reporting of clinically relevant adverse events. Not surprisingly, the incidence of hyperkalemia was higher with MRAs. The risk of renal dysfunction or potassium derangements with MRAs is potentiated in HFrEF by the concomitant use of angiotensin-converting enzyme inhibitors and/or angiotensin II receptor blockers. When interpreting and applying these data to clinical practice, it should be noted that all patients with renal impairment (serum creatinine level $>220 \mu \mathrm{mol} / \mathrm{L}$ or estimated glomerular filtration rate $<30 \mathrm{~mL} / \mathrm{min}$ ) or hyperkalemia (serum potassium level $>5.0 \mathrm{mmol} / \mathrm{L}$ ) at baseline were excluded. After the publication of the RALES trial, a Canadian population-based cohort study demonstrated an increase in hyperkalemiarelated hospitalizations and death that coincided with an increase in outpatient spironolactone prescribing (6). However, this risk may be mitigated in practice by increasing the frequency of bloodwork monitoring. A subsequent longitudinal population-based study from the United Kingdom (17) demonstrated that increased monitoring of serum creatinine and potassium, in parallel with increased prescribing of spironolactone, did not result in an increased rate of hyperkalemia-related hospitalizations. Therefore, careful selection of appropriate patients in which to initiate MRAs and frequent follow-up is imperative.

The incidence of hospitalization due to HF was significantly reduced with MRAs; however, a benefit was not observed in hospitalizations from any cause. Notably, both hospitalization outcomes were associated with high statistical heterogeneity. This is likely due to differences in the populations studied. Hospitalization from any cause was only reported in two of the three studies and was primarily driven by the Eplerenone, a Selective Aldosterone Blocker, in Patients with Left Ventricular Dysfunction after Myocardial Infarction (EPHESUS) trial, which enrolled patients with new-onset HF after an acute myocardial infarction (MI) (9). In this trial, eplerenone reduced HF hospitalizations compared with placebo but did not reduce overall hospitalizations, which occurred at a much higher rate (10\% versus $45 \%$, respectively). Therefore, hospitalization unrelated to $\mathrm{HF}$ occurred more frequently in these patients, which was not mitigated by eplerenone. This result was not unforeseen because patients who develop HF post-MI will often require multiple repeat hospitalizations, as demonstrated in a large cohort study involving patients $\geq 65$ years of age admitted for an acute MI (18). Patients who developed HF while in hospital post-MI, as opposed to those who did not, had a higher incidence of rehospitalization for ischemic heart disease, atrial fibrillation and ventricular arrhythmias over a five-year period.

With appropriate monitoring, it appears that MRAs are safe and, overall, result in a significant reduction in death from any cause, which could be interpreted as a balanced assessment of benefit versus risk. This conclusion is consistent with current guideline recommendations advocating the use of MRAs in patients with HFrEF (2-5). Despite these recommendations, the use of MRAs in practice remains low, potentially due to safety concerns. An observational cohort analysis of 43,000 patients in the United States (19) demonstrated the use of MRAs in indicated HF patients was only $34 \%$, although this analysis was unable to account for patients with hyperkalemia or renal dysfunction. A more recent treatment gap analysis from the United States determined that if all patients with HF and an indication for an MRA received appropriate therapy (based on the assumption that $64 \%$ of eligible patients are not currently treated), approximately 21,000 deaths would be prevented per year (20).

The primary strengths of the present review are the comprehensive systematic search strategy and the inclusion of only placebo-controlled trials with clinically relevant end points. That only three studies were included demonstrates a large number of trials in the published literature are of poor methodological quality (ie, not randomized) or only investigate surrogate end points, which may not translate into clinical efficacy. Although the present review was limited to studies published in English, only two studies were excluded based on this restriction, and the enrollment of both studies combined was small (73 patients) and unlikely to have impacted the results. A potential perceived limitation is the inclusion of clinically heterogeneous HFrEF patient populations. However, the aim of the present review was to include any patients with a reduced LVEF so the safety and efficacy results would be generalizable to all HFrEF patients. As with all meta-analyses, the results are restricted by the inherent limitations of the design and reporting of the included studies. These primarily consist of incomplete reporting of adverse events and short duration of follow-up (up to a mean of 24 months).

The present meta-analysis demonstrates that MRA therapy in patients with HFrEF reduced all-cause mortality by $19 \%$ despite a 1.4 fold higher incidence of hyperkalemia. The rates of other clinically relevant safety outcomes were not consistently reported. The rate of $\mathrm{CV}$ mortality and hospitalization due to HF were also reduced by $20 \%$ and $24 \%$, respectively, although the latter was associated with high statistical heterogeneity. The rate of hospitalization for any cause was not significantly reduced with MRA therapy. Overall, the present review highlights the benefit of MRAs across the spectrum of HFrEF, which encompasses patients with multiple etiologies and symptom severity, despite a higher incidence of hyperkalemia. Therefore, MRA therapy should not be withheld from appropriately selected patients (based on the inclusion criteria of the included trials) because the risk of adverse events does not appear to exceed the overall benefit in mortality reduction.

ACKNOWLEDGEMENTS: The authors thank Sandy Campbell, medical librarian at the JW Scott Health Sciences Library, University of Alberta, Edmonton, Alberta, for her assistance with the literature search.

FUNDING SOURCES: This study was unfunded.

DISCLOSURES: Data from this study were presented in poster format at Vascular 2013, October 17 to 20, 2013, in Montreal, Quebec. The authors have no conflicts of interest related to this work. 


\section{Barry et al}

\section{REFERENCES}

1. Go AS, Mozaffarian D, Roger VL, et al. Heart disease and stroke statistics - 2014 update: A report from the American Heart Association. Circulation 2014;129:e28-e292.

2. Arnold JM, Liu P, Demers C, et al. Canadian Cardiovascular Society consensus conference recommendations on heart failure 2006: Diagnosis and management. Can J Cardiol 2006;22:23-45.

3. Yancy CW, Jessup M, Bozkurt B, et al. 2013 ACCF/AHA guideline for the management of heart failure: $A$ report of the American College of Cardiology Foundation/American Heart Association task force on practice guidelines. J Am Coll Cardiol 2013;62:e147-239.

4. McKelvie RS, Moe GW, Ezekowitz JA, et al. The 2012 Canadian Cardiovascular Society heart failure management guidelines update: Focus on acute and chronic heart failure. Can J Cardiol 2013;29:168-81.

5. McMurray JJV, Adamopoulos S, Anker SD, et al. ESC guidelines for the diagnosis and treatment of acute and chronic heart failure 2012: The task force for the diagnosis and treatment of acute and chronic heart failure 2012 of the European Society of Cardiology. Developed in collaboration with the Heart Failure Association (HFA) of the ESC. Eur Heart J 2012;33:1787-847.

6. Juurlink DN, Mamdani MM, Less DS, et al. Rates of hyperkalemia after publication of the randomized aldactone evaluation study. N Engl J Med 2004;351:543-51.

7. Jadad AR, Moore RA, Carroll D, et al. Assessing the quality of reports of randomized clinical trials: is blinding necessary? Controlled Clin Trials 1996;17:1-12.

8. Pitt B, Zannad F, Remme WJ, et al. The effect of spironolactone on morbidity and mortality in patients with severe heart failure. N Engl J Med 1999;341:709-17.

9. Pitt B, Remme W, Zannad F, et al. Eplerenone, a selective aldosterone blocker, in patients with left ventricular dysfunction after myocardial infarction. N Engl J Med 2003;348:1309-21.

10. Zannad F, McMurray JJV, Krum H, et al. Eplerenone in patients with systolic heart failure and mild symptoms. N Engl J Med 2011;364:11-21.
11. Ezekowitz JA, McAlister FA. Aldosterone blockage and left ventricular dysfunction: A systematic review of randomized clinical trials. Eur Heart J 2009;30:469-77.

12. Schäfer A, Fraccarollo D, Hildemann SK, Tas P, Ertl G, Bauersachs J. Addition of the selective aldosterone antagonist eplerenone to ACE inhibition in heart failure: Effect on endothelial dysfunction. Cardiovasc Res 2003;58:655-62.

13. Bos R, Mougenot N, Findji L, Médiani O, Vanhoutte PM, Lechat P. Inhibition of catecholamine-induced cardiac fibrosis by an aldosterone antagonist. J Cardiovasc Pharmacol 2005;45:8-13.

14. Keidar S, Gamliel-Lazarovich A, Kaplan M, et al. Mineralocorticoid receptor blocker increases angiotensin-converting enzyme 2 activity in congestive heart failure patients. Circ Res 2005;97:946-53.

15. Bauersachs J, Fraccarollo D, Ertl G, Gretz N, Wehling M, Christ M. Striking evidence of natriuresis by low-dose spironolactone in congestive heart failure only in combination with ACE inhibition: Mechanistic evidence to support RALES. Circulation 2000;102:2325-8.

16. Farquharson CA, Struthers AD. Spironolactone increases nitric oxide bioactivity, improves endothelial vasodilator dysfunction, and suppresses vascular angiotensin I/angiotensin II conversion in patients with chronic heart failure. Circulation 2000;101:594-7.

17. Wei L, Struthers AD, Fahey T, Watson AD, MacDonald TM. Spironolactone use and renal toxicity: Population based longitudinal analysis. BMJ 2010;340:c1768.

18. Ezekowitz JA, Kaul P, Bakal JA, Armstrong PA, Welsh RC, McAlister FA. Declining in-hospital mortality and increasing heart failure incidence in elderly patients with first myocardial infarction. J Am Coll Cardiol 2009;53:13-20.

19. Albert NM, Yancy CW, Liang L, et al. Use of aldosterone antagonists in heart failure. JAMA 2009;302:1658-65.

20. Fonarow GC, Yancy CW, Hernandez AF, Peterson ED, Spertus JA, Heidenreich PA. Potential impact of optimal implementation of evidence-based heart failure therapies on mortality. Am Heart J 2011;161:1024-30. 